\title{
Las Tradiciones Peruanas como legado de Ricardo Palma a la sociedad peruana
}

\author{
Marco Martos \\ Academia Peruana de la Lengua \\ marcomartos9@hotmail.com \\ Lima-Perú
}

\section{Resumen}

El texto se refiere de modo general a las Tradiciones Peruanas de Ricardo Palma y a través de algunos ejemplos de ellas, las referidas a Francisco de Carbajal, infiere la idea del Perú que tiene el escritor estudiado. La noción de patria que Palma tiene es la de un ideal común en permanente construcción que si bien nace en el pasado se hará mejor en el porvenir. Palma está lejos de la arcadia colonial, pero tampoco se solaza con el presente republicano que conoció; tiene pesimismo del presente y del pasado, pero confianza en el futuro; fue un intelectual orgánico de la sociedad peruana.

Palabras clave: Palma, intelectual orgánico, Tradiciones peruanas.

\begin{abstract}
:
The text refers in a general way to the Peruvian Traditions of Ricardo Palma; and through some examples of them, those referring to Francisco de Carbajal, it infers the idea of Peru that Palma has. His notion of homeland is that of a common ideal in permanent construction which will become better in the future, although it was born in the past. Palma is far from the colonial arcadia, but he is not happy with the republican present that he knew. He has pessimism of the present and the past, but confidence in the future. He was an organic intellectual of Peruvian society.
\end{abstract}

Keywords: Palma, organic intellectual, Peruvian Traditions 
Marco Martos Carrera (Perú): Escritor, poeta y periodista peruano. Es considerado uno de los principales representantes de la Generación del 60 en la poesía peruana. Presidente de la Academia Peruana de la Lengua, catedrático de la Universidad Nacional Mayor de San Marcos y ex decano de la Facultad de Letras y Ciencias Humanas de dicha casa de estudios. Es miembro de Número del Instituto Ricardo Palma. 
A lo largo del tiempo, los que nos llamamos peruanos vamos formando nuestra identidad que se hunde en el pasado y se proyecta al porvenir. Consideramos nuestras a todas las culturas que vivieron en el territorio que habitamos desde el principio del principio, aunque las conozcamos apenas; son nuestras porque aquí siempre estuvieron y sus genes permanecen entre nosotros. Somos un conglomerado de pueblos y una esperanza permanente de lo que seremos. El nombre de nuestro país se conoce por lo menos desde 1523, diez años antes de la conquista española por el oro de la expedición de Pascual de Andagoya que lo había habido de un viaje al Perú, aunque es verdad que el susodicho no llegó al territorio nuestro. Los españoles llamaban Perú a la región inexplorada al sur de Panamá y así la denominaba Francisco Pizarro cuando emprendió su viaje de conquista. En tiempos del cronista Pedro Cieza de León, a mediados del siglo XVI, ya estaban definidos los territorios que conforman la región histórica del Perú y se entendía que era desde Quito hasta la villa de Plata. En todo el tiempo del virreinato se fueron conformando las diferentes naciones y el territorio y un sentimiento colectivo de pertenencia se fue definiendo cada vez con características más rotundas y definitivas.

En la vida de las naciones hay un tiempo corto, marcado por las necesidades perentorias, por los quehaceres diarios con un continuo resolver situaciones que se van presentando y hay tiempo subterráneo, potente, secreto, un río continuo, sin prisa ni pausa, que va definiendo realidades y asegura la duración, la permanencia, la búsqueda de futuro. El tiempo corto lo hacemos todos a lo largo de nuestras vidas, el tiempo largo siempre es colectivo, tiene grandes tareas, pertenece como el otro a todos, pero se encarna en algunos hombres y mujeres que por alguna razón son ejemplares, modelos de ciudadanos. De esa laya son los artistas y escritores que los pobladores recordamos con unción. El primero de ellos es el Inca Garcilaso 
en el siglo XVI que encarna desde el lado mestizo a la nación que estaba surgiendo, y desde el lado de los pueblos originarios está sin duda Guamán Poma de Ayala, expresándose en dibujos y en una prosa ríspida que trata de apoderarse de la lengua de los conquistadores. Esa tensión en cierto sentido continúa hasta hoy día, solo que pasados cinco siglos son más numerosos los peruanos que tienen como propia la lengua de Castilla. Hubo de pasar varios siglos para que nos naciese otro escritor que nos encarne: Ricardo Palma (1833-1919). Con una gracia sin par, historia y literatura se dan la mano en sus escritos. Palma es, en la terminología de Antonio Gramsci, un intelectual orgánico de la sociedad peruana, alguien que enhebra en cada uno de sus actos un ideal colectivo. Palma fue un intelectual completo, fuerte en matemáticas desde la época escolar, contador de la Armada Peruana, periodista, lexicógrafo, fundador de la Academia Peruana de la Lengua en 1887, senador de la República, defensor apasionado del modo de hablar de los peruanos, bibliotecario por excelencia. Y todo lo que hizo se materializa en el Palma que conocemos y celebramos.

En una carta a su amigo, el escritor argentino Pastor Obligado, recogida por Héctor Martínez López en "El Comercio" de Lima, del 6 de octubre de 2019, escribe Palma: "Me vino a mientes platear píldoras, y dárselas a tragar al pueblo, sin andarme en escrúpulos de monja boba. Algo y aún algos de mentira, y tal o cual dosis de verdad, por infinitesimal que sea, mucho de esmero y pulimento del lenguaje, y cata la receta para escribir tradiciones". Palma bromea, incluso cuando habla en serio como es el caso. Liberado de las exigencias de la historia, del cotejo de fuentes, por ejemplo, puede libremente ofrecer sus pequeños cuentos, aderezarlos con mentiras por conveniencia del relato, y abur, la narración está hecha y el lector queda hechizado. Un ejemplo que proponemos es la tradición que se llama "El demonio de los Andes", dedicada a Francisco de Carbajal. Empieza así: 
Arévalo, pequeña ciudad de Castilla la Vieja dio cuna al soldado que por su indómita bravura, por sus dotes militares, por sus hazañas, que rayan en lo fantástico, por su rara fortuna en los combates y por su carácter sarcástico y cruel fue conocido, en los primeros tiempos del coloniaje, con el nombre de Demonio de los Andes.

¿Quiénes fueron sus padres? ¿Fue hijo de ganancia o fruto de honrado matrimonio? La historia guarda sobre estos puntos, si bien libro hemos leído en que se afirma que fue hijo natural del terrible César Borgia, duque de Valentinois.

Sobre César Borgia, siguiendo las opiniones de Álvaro Mutis, debe recordarse que este príncipe y guerrero buscó con avidez el poder y lo logró sin tener en cuenta los medios usados para conseguirlo. Jamás dijo a los pueblos que gobernara que su único compromiso era con los desvalidos y con su patria amada. Jamás prometió garantías a los banqueros e industriales para desarrollar sus actividades dentro de las normas de la ley y en beneficio de todos. Jamás engañó a nadie sobre sus intenciones, que fueron siempre bien claras y simples: obtener el poder y conservarlo a toda costa. De él escribió el propio Mutis:

\section{Funeral en Viana}

In memoriam Ernesto Volkening

Hoy entierran en la iglesia de Santa María de Viana

a César, Duque de Valentinois. Preside el duelo

su cuñado Juan de Albret, Rey de Navarra.

En el estrecho ámbito de la iglesia

de altas naves de un gótico tardío,

se amontonan prelados y hombres de armas.

Un olor a cirio, a rancio sudor, a correajes 
y arreos de milicia, flota denso en la lluviosa madrugada. Las voces de los monjes llegan desde el coro con una cristalina serenidad sin tiempo.

César yace en actitud de leve asombro, de incómoda espera. El rostro lastimado por los cascos de su propio caballo conserva aún ese gesto de rechazo cortés, de fuerza contenida, de vago fastidio, que en vida le valió tantos enemigos. La boca cerrada con firmeza parece detener A flor de labio una airada maldición castrense. Las manos perfiladas y hermosas, las mismas de su hermana Lucrezia, Duquesa d'Este, detienen apenas la espada regalo del Duque de Borgoña. Chocan las armas y las espuelas en las losas del piso, se acomoda una silla con un apagado chirrido de madera contra el mármol, una tos contenida por el guante ceremonial de un caballero. Cómo sorprende este silencio militar y dolorido ante la muerte de quien siempre vivió entre la algarabía de los campamentos, el estruendo de las batallas y las músicas $\mathrm{y}$ risas de las fiestas romanas. Inconcebible que calle esa voz, casi femenina, que con el acento recio y pedregoso de su habla catalana, ordenaba la ejecución de prisioneros, recitaba largas tiradas de Horacio con un aire de fiebre y sueño o murmuraba al oído de las damas una propuesta bestial.

Los altos muros de piedra, las delgadas columnas reunidas en haces que van a perderse en la obscuridad de la bóveda, dan al canto una desnudez reveladora, una insoslayable evidencia. 
Sólo Dios escucha, decide y concede.

Todos los presentes parecen esfumarse

ante las palabras con las que César, por boca

de los oficiantes, implora al Altísimo un don

que en vida le hubiera sido inconcebible: la misericordia.

El perdón de sus errores y extravíos no fue asunto para ocupar ni el más efímero instante de sus días.

Sin sosiego los días de César, Duque de Valentinois, Duque de Romaña, Señor de Urbino.

¿De qué fuente secreta manaba la ebria energía de sus pasiones y la helada parsimonia de sus gestos?

Los hombres habían comenzado a tejer la leyenda de su vida sin esperar a su muerte. Algo de esto llegó alguna vez a sus oídos. No se marcó el más leve interés en sus facciones.

Una humedad canina se demora dentro de la iglesia y entumece los miembros de los asistentes.

El desnudo acero de las espadas y de las alabardas en alto despide una luz pálida, un nimbo impersonal y helado. Los arreos de guerra exhalan un agrio vaho de resignado cansancio.

El Rey Juan de Navarra mira absorto las yertas facciones de su cuñado por las-que cruza, en inciertas ráfagas, la luz de los cirios. Vuelven a su memoria los consejos que días antes le daba César para vencer las fortificaciones aragonesas; la precisión de su lenguaje, la concisa sabiduría de su experiencia, la severa moderación de sus gestos, tan ajena al febril desorden de su rostro en las interminables orgías de la corte papal. Juan de Albret y su séquito asisten 
al descenso a tierra sagrada de quien en vida fue soldado excepcional, señor prudente y justo en sus estados, amigo de Leonardo da Vinci, ejecutor impávido de quienes cruzaron su camino, insaciable abrevador de sus sentidos y lector asiduo de los poetas latinos: César, Duque de Valentinois, Duque de Romaña, Gonfaloniero Mayor de la Iglesia, digno vástago de los Borja, Milá y Montcada, nobles señores que movieron pendón en las marcas de Cataluña y de Valencia y augustos prelados al servicio de la Corte de Roma. Dios se apiade de su alma.

(Mutis, 1982, p. 129)

Sin duda, quien lea la tradición de Palma sobre Carbajal y conozca la poesía de Álvaro Mutis y algo de la vida de César Borgia puede jugar con la posibilidad de un parentesco filial entre ambas figuras históricas. Solo que hay un pequeño problema. César Borgia nació el 13 de septiembre de 1475 en Roma. Hijo de Rodrigo Borja o Borgia, después papa Alejandro VI y hermano de Lucrecia Borgia. Es nombrado obispo a los dieciséis años y cardenal a los dieciocho, aunque pronto abandonó la carrera eclesiástica por la de las armas. En cambio Francisco de Carbajal nació en 1464 y murió en 1548. Tenía diez años cuando nacía César Borgia. El único parentesco entre ambas figuras históricas es el de la crueldad, el ejercicio despiadado del poder por el poder, por el deseo de conservarlo a toda costa. $\mathrm{Y}$ eso es justamente lo que hace universales a ambas figuras, les da una familiaridad que Palma convierte en lazos de sangre. Son dos modelos de dictadores en los campos de batalla. Pero también de dos valientes que despiertan admiración. Palma cuenta que después del final trágico que tuvo Francisco Pizarro, el conquistador del Perú, Carbajal combatió tenazmente a la facción del joven Almagro. En la sangrienta batalla de Chupas, 
de setiembre de 1542 derrotó a Diego de Almagro, el joven, quien fue hecho prisionero y más tarde decapitado en Cusco. En medio del combate, Carbajal estimulaba a los suyos: "iMengua y baldón para el que retroceda!” Obeso y entrado en años parecía un jovencito en medio de las trifulcas sangrientas. Cuando vinieron los tiempos de las ordenanzas en favor de los indios de Bartolomé de las Casas, Carbajal presintió el desarrollo de los hechos y deseó regresar a España, pero sabiendo que era importante en el bando de los Pizarro, se transformó en Maese de Campo de Gonzalo Pizarro y le aconsejó que se hiciera del gobierno y que después se haga lo que más convenga. Como estratega, lo que está sugiriendo es avanzar en la rebelión y tal vez después pactar con los enviados del rey. En el decir de Palma, Carbajal era un hombre que se adelantaba a su época pues hogaño a una revolución vencida se le llama motín, a un motín triunfante se le llama revolución. Entrelíneas hay una admiración de Palma por Carbajal, quien octogenario exterminó o aterró a los realistas del sur, atravesó los Andes a caballo, de Quito a San Miguel de Lima, o a Guamanga, de Guamanga a Lima, de Lucanas al Cusco, del Collao a Arequipa, y de Arequipa a Charcas. Comiendo y durmiendo sobre el caballo, insensible a los hielos de la puna, a la ardiente reverberación del sol en los arenales y a las privaciones y fatigas de las marchas forzadas. El vulgo, sostiene Palma, poniendo estas palabras en boca de un historiador no identificado, decía que Carbajal y su caballo andaban por los aires. Después de la batalla de Iñaquito, el poder de Gonzalo Pizarro parecía indestructible y volvió Carbajal a decirle que la rebelión triunfante se justifica en sí misma y que es el tiempo de gobierno el que otorga la legitimidad y que ningún rey recibe el nombre de traidor. Escribe Palma que estaba escrito que no estaba escrito que no era Gonzalo Pizarro el escogido por Dios para crear la nacionalidad peruana. Y en esta frase queremos detenernos para analizarla y subrayar que Palma asocia la idea de nación a la idea de libertad. El Perú, pues, no es una nación existente desde el principio de los 
tiempos, es algo que se va haciendo y su lugar está siempre en el futuro. Basta esa sola frase de Palma para desvirtuar todos los intentos de hacerlo un pasadista, un admirador incondicional de la época del virreinato, para consagrarlo como un ciudadano peruano ejemplar. (1964, p. 239)

Del Perú la suprema independencia

Carbajal ha tres siglos quería

Y quererlo costóle la existencia

Estos, versos, según Palma adornaban un retrato del Demonio de los Andes en el Palacio de la Exposición de Lima. Escribe Palma:

Cuéntase que en el Cusco, doña María Calderón, esposa de un capitán de la tropa de Centeno, se permitía con mujeril indiscreción tratar a Gonzalo de tirano, y repetía en público que el rey no tardaría en triunfar de los rebeldes.

-Comadrita- le dijo Carbajal en tres distintas ocasionestráguese usted las palabras, porque si no contiene su maldita sin hueso la hago matar, como hay Dios, sin que la valga el parentesco espiritual que conmigo tiene.

Luego que vio la inutilidad de la tercera moción, se presentó el maestre en casa de la señora diciéndole: -Sepa usted señora doña comadre que vengo a darle garrote- $Y$ después de haber expuesto el cadáver en una ventana, exclamó: -iCuerpo de tal comadre cotorrita que si usted no escarmienta de esta yo no sé lo que me haga! (Palma, 1996, p. 240)

Como se dice popularmente, Carbajal no se andaba en chiquitas y ahorcaba a cuanto prójimo se oponía a sus designios como ocurre en "Los tres motivos del oidor" donde aparece que ahorcó 
a Pedro del Barco y Machín de Florencia, hombres de fuste que estuvieron entre los primeros conquistadores que capturaron a Atahualpa en la plaza de Cajamarca.

A lo largo de sus escritos, Palma en ningún momento piensa en una arcadia colonial, sino que al contrario, con su prosa zumbona hace escarnio de las costumbres ridículas de los españoles afincados en el Perú que se disputan por cosas nimias, como qué propietario de qué carroza tiene mayor derecho para pasar primero por una calle o si la iglesia de San Pedro puede tener tres o dos puertas. Palma tenía una actitud republicana, de clase media, como Segura y como Pardo; desde ese horizonte, concebía al Perú como totalidad, aunque como bien sabemos ahora, esa totalidad excluía a casi todos los pobladores de la selva. Lo que le atraía de la selva era lo fantástico, lo fabuloso, lo no sabido, o la figura del rebelde Lope de Aguirre, enfrentado al mismo rey en lo enmarañado de los bosques, en las corrientes del río Marañón. Era sin duda un grande, porque veía al Perú con ilusión, porque consideraba que todo merecía hacerse por nuestra patria, porque predicaba con el ejemplo: fundar la Academia Peruana de la Lengua y defender nuestra manera de hablar con ardor, escribir poesías y tradiciones, refundar la Biblioteca Nacional del Perú, ser un intelectual orgánico no de una facción o partido, sino de todo el Perú. Por eso su pluma se hunde en el pasado y nos presenta a Atahualpa jugando ajedrez con los conquistadores, o a Bolívar propugnando la libertad. En los primeros tiempos de la patria fuimos afortunados teniendo al inca Garcilaso, en el siglo IXX lo fuimos cuando nos nació Ricardo Palma, y en horas más cercanas con César Vallejo y José María Arguedas. Estos escritores nos refuerzan en nuestro ser, certifican nuestro orgullo de ser peruanos, de procurar ser mejores en el porvenir. 


\section{Bibliografía}

Palma, R. (1964). Tradiciones peruanas completas. Edición y prólogo de Edith Palma. Madrid: Aguilar.

Palma, R. (1996). Tradiciones peruanas. Edición crítica Julio Ortega y Flor María Rodríguez Arenas, coordinadores. Colección Archivos, 23. Madrid: ALLCA XX.

López Martínez, H. (2019). “Ricardo Palma y El Comercio”. En "El Comercio”. Lima, 6 de octubre de 2019.

Mutis, Á. (1982). Poesía y prosa. Bogotá: Instituto Colombiano de Cultura.

Recibido el 10 de octubre de 2019 Aceptado el 30 de octubre de 2019 